\title{
NPR1 Differentially Interacts with Members of the TGA/OBF Family of Transcription Factors That Bind an Element of the PR-1 Gene Required for Induction by Salicylic Acid
}

\author{
Jun-Ma Zhou, ${ }^{1}$ Youssef Trifa, ${ }^{1}$ Herman Silva, ${ }^{1}$ Dominique Pontier, ${ }^{2}$ Eric Lam, ${ }^{2}$ Jyoti Shah,,${ }^{1}$ and \\ Daniel F. Klessig' \\ ${ }^{1}$ Waksman Institute and Department of Molecular Biology and Biochemistry, Rutgers, The State University \\ of New Jersey, 190 Frelinghuysen Road, Piscataway 08854-8020, U.S.A.; ${ }^{2}$ AgBiotech Center, Cook \\ College, Foran Hall, Rutgers, The State University of New Jersey, 59 Dudley Road, New Brunswick \\ 08903, U.S.A. \\ Accepted 21 October 1999.
}

\begin{abstract}
NPR1 is a critical component of the salicylic acid (SA)mediated signal transduction pathway leading to the induction of defense genes, such as the pathogenesis-related $(P R)-1$ gene, and enhanced disease resistance. Using a yeast two-hybrid screen, we identified several NPR1interacting proteins (NIPs). Two of these NIPs are members of the TGA/OBF family of basic leucine zipper (bZIP) transcription factors; this family has been implicated in the activation of SA-responsive genes, including $P R-1$. Six TGA family members were tested and shown to differentially interact with NPR1: TGA2 and TGA3 showed strong affinity for NPR1; TGA5 and TGA6 exhibited weaker affinity; and TGA1 and TGA4 displayed little or no detectable interaction with NPR1, respectively. Interestingly, the amino-termini of these factors were found to decrease their stability in yeast and differentially affect their apparent affinity toward NPR1. The interacting regions on NPR1 and the TGA factors were also defined. Each of four point mutations in NPR1 that disrupt SA signaling in Arabidopsis completely blocked interaction of NPR1 with TGA2 and TGA3. TGA2 and TGA3 were also found to bind the SA-responsive element of the Arabidopsis $P R-1$ promoter. These results directly link NPR1 to SAinduced $P R-1$ expression through members of the TGA family of transcription factors.
\end{abstract}

Plants resisting pathogen attack rapidly activate a wide variety of defenses in the inoculated leaves that help prevent pathogen colonization, including the generation of reactive oxygen species (ROS), the reinforcement of cell walls, and the

Corresponding author: Daniel F. Klessig; Fax: 1-732-445-5735; E-mail: klessig@mbcl.rutgers.edu

Current address of Herman Silva: Department of Biology, Faculty of Sciences, University of Chile, Casilla 653, Santiago, Chile.

Current address of Jyoti Shah: Division of Biology, Kansas State University, 303 Ackert Hall, Manhattan 66506, U.S.A. synthesis of antimicrobial compounds termed phytoalexins. At slightly later times, the infected leaves develop a hypersensitive response (HR), in which necrotic lesions are formed at the sites of pathogen entry and the pathogen is restricted to these regions. Correlating with or slightly preceding the appearance of an HR is the accumulation of salicylic acid (SA) and the expression of several classes of pathogenesis-related (PR) proteins, many of which exhibit antimicrobial activity. Subsequent to these responses, increased $P R$ gene expression is detected in the uninoculated portions of the plant, where it coincides with the appearance of systemic acquired resistance (SAR). SAR is a long-lasting and broad-based resistance to secondary infections by a wide variety of pathogens (Dempsey et al. 1999).

Efforts to elucidate the signal transduction pathway leading to these defense responses have begun to provide clues as to how disease resistance is activated. A variety of studies have revealed that SA is an important signal in this process. Exogenously supplied SA enhances disease resistance in many plant species, and induces the same classes of PR proteins as those expressed during SAR (Malamy and Klessig 1992). In addition, SA appears to be involved in the activation of HR cell death and the restriction of pathogen spread (Dempsey et al. 1999). The strongest evidence that SA plays a critical role in signaling defense responses has come from studies of plants in which SA accumulation is prevented either by an SA biosynthesis inhibitor or by the expression of a transgene. These plants fail to develop SAR and/or exhibit heightened susceptibility to pathogen infection (Delaney et al. 1994; Gaffney et al. 1993; Pallas et al. 1996; Mauch-Mani and Slusarenko 1996).

Several components of the SA-mediated signaling pathway leading to disease resistance have been identified through the analysis of Arabidopsis mutants exhibiting aberrant SAR responses. Some of these components appear to act upstream of SA. For example, mutations in the acd2 (accelerated cell death; Greenberg et al. 1994), $\operatorname{cim} 3$ (constitutive immunity; Ryals et al. 1996), lsd (lesion simulating disease resistance response; Dietrich et al. 1994; Weymann et al. 1995), сер 
(constitutive expression of $\underline{P} R$ genes; Silva et al. 1999), ssil (suppressor of salicylate insensitivity of $n p r 1-5$; Shah et al. 1999), dndl (defense with no HR cell death; Yu et al. 1998), and $c p r$ (constitutive expressor of $\underline{P R}$ genes; Bowling et al. 1994, 1997; Clarke et al. 1998) loci confer elevated levels of $\mathrm{SA}$, as well as constitutive $P R$ gene expression and SAR. By contrast, the protein encoded by the nprl (nonexpressor of $\underline{P R}$ genes; Cao et al. 1994; Glazebrook et al. 1996; Shah et al. 1997)/niml (noninducible immunity; Delaney et al. 1995) locus appears to function downstream of SA. Plants carrying mutations in this gene fail to develop enhanced disease resistance or express $P R$ genes, including $P R-1$ (whose expression serves as an excellent molecular marker of disease resistance), following pathogen infection or treatment with SA or its functional analogs INA (2,6-dichloroisonicotinic acid) or BTH (benzothiadiazole).

NPR1 was recently cloned and shown to encode a novel protein containing ankyrin repeats (Cao et al. 1997; Ryals et al. 1997). These repeats, which are often involved in proteinprotein interactions, appear to be important for NPR1 function, as most of the mutations that disrupt NPR1 function are located within them (Cao et al. 1997; Ryals et al. 1997; Shah et al. 1999). NPR1 also shares limited homology with the transcription regulator I $\kappa \mathrm{B} \alpha$ (Ryals et al. 1997). In mammals, $\mathrm{I} \kappa \mathrm{B}$ proteins repress the pathways leading to inflammatory and immune responses by binding the transcription factor NF$\mathrm{\kappa B}$ and thereby sequestering it in the cytosol. Activation of these defense pathways occurs when, in response to the appropriate stimulus, I $\kappa \mathrm{B}$ is phosphorylated and degraded. This enables NF- $\kappa B$ to be translocated into the nucleus, where it activates defense gene expression (Baeuerle and Baltimore 1996).

Despite the homology between NPR1 and I $\mathrm{KB} \alpha$, it is not clear whether these proteins regulate their respective defense pathways through analogous mechanisms. Unlike $\mathrm{I} \kappa \mathrm{B} \alpha$, NPR1 appears to function as a positive regulator of defense responses. Overexpression of NPR1 in both wild-type and nprl mutant plants conferred enhanced disease resistance to bacterial and fungal pathogens. In addition, these plants exhibited stronger expression of the $P R$ genes following pathogen infection (Cao et al. 1997, 1998). However, since overexpression of NPR1 did not cause constitutive activation of defense responses, NPR1 (or possibly a coinducer) may require activation by pathogen attack or SA before SAR can be induced (Cao et al. 1998; Ryals et al. 1997).

To gain a greater understanding of how NPR1 signals the activation of defense responses, we have searched for NPR1interacting proteins (NIPs). Using a yeast two-hybrid system, we identified several members of the TGA/OBF family of basic leucine zipper (bZIP) transcription factors as NIPs. This family of transcription factors recognizes the TGACG/as-1/ ocs elements in the promoters of a variety of plant and plant pathogen genes, including those regulating the expression of Arabidopsis and tobacco $P R-1$, Arabidopsis, tobacco, and soybean glutathione S-transferase (GST), Agrobacterium tumefaciens octopine synthase (ocs) and nopaline synthase (nos), and the Cauliflower mosaic virus 35S promoter (Katagiri et al. 1989; Zhang et al. 1993; Ulmasov et al. 1995; Chen et al. 1996; Xiang et al. 1997; Lebel et al. 1998; Strompen et al. 1998). Interestingly, mutational analyses have indicated that these elements are, at least in part, responsible for the SA responsiveness of these genes/promoters. In addition, SA treatment increases the TGACG/as-1 binding activity in nuclear extracts prepared from treated tobacco leaves (Jupin and Chua 1996; Stange et al. 1997). Thus, our discovery that NPR1 interacts with several members of the TGA family of transcription factors provides a mechanism through which this critical SA signaling component regulates the expression of SA-induced genes, such as $P R-1$.

\section{RESULTS}

\section{Identification of NIPs.}

A GAL4-based, yeast two-hybrid screen was developed to facilitate the identification of NIPs (Fields and Song 1989). The entire open reading frame of NPRl was fused in-frame behind the GAL4 DNA binding (DB) domain (amino acids [aa] 1 to 147) in the "bait" vector pBI880 and transformed into yeast strain PJ69-4A. This yeast strain contains three reporter genes (His3, Ade2, and LacZ), each regulated by separate GAL promoters and integrated into the genome (James et al. 1996). The "prey" library contained cDNAs generated from Arabidopsis cloned behind the GAL4 transcriptional activation (TA) domain in prey vector $\mathrm{pBI771}$. After transformation with this prey library, yeast colonies carrying pBI880-NPRI were selected based on their ability to grow on media lacking histidine (His). These $\mathrm{His}^{+}$transformants were then rescreened for their ability to grow on media lacking either His or adenine (Ade) and the resulting $\mathrm{His}^{+} \mathrm{Ade}^{+}$colonies were screened for $\beta$-galactosidase $(\beta$-gal; LacZ) activity in liquid culture. Twenty $\mathrm{His}^{+} \mathrm{Ade}^{+} \mathrm{LacZ}^{+}$colonies were obtained from $7 \times 10^{7}$ initial transformants. Following plasmid rescue and retransformation into GAL4 DB:NPR1-expressing PJ69-4A, approximately half of these pBI771 constructs were able to confer the $\mathrm{His}^{+} \mathrm{Ade}^{+} \mathrm{LacZ}^{+}$phenotype. Partial sequence analyses of the cDNA inserts in nine of the transformants indicated that they belonged to three distinct classes. One class, containing four members, is described here.

The four cDNAs constituting this class were sequenced in their entirety. Two encoded identical $\mathrm{N}$-terminal $(\mathrm{N}-\mathrm{t}$ )-deleted forms of TGA1 ( $\Delta 1$ to 75 aa ), while the other two cDNAs encoded identical $\mathrm{N}$-t-deleted forms of OBF5 (TGA5; $\Delta 1$ to 139 aa); TGA1 and TGA5 are members of the TGA/OBF family of transcription factors (Xiang et al. 1997). Retransformation of these cDNAs into GALA DB:NPRl-expressing yeast confirmed that the truncated forms of TGA1 and TGA5 interact with NPR1 (Fig. 1A,B). Moreover, in the absence of NPR1 (empty bait vector), neither transformant grew on media lacking either His or Ade. Similarly, GALA DB:NPR1containing yeast were unable to multiply on these media in the absence of TGA1 or TGA5 (empty prey vector). Thus, coexpression of NPRI with either truncated TGAl or truncated $T G A 5$ was required for His and Ade prototrophy.

\section{TGA family members exhibit differential interaction with NPR1.}

In Arabidopsis, six members of the TGA/OBF family of transcription factors have been identified and compared (Xiang et al. 1997). To determine whether they all interact similarly with NPR1, full-length cDNAs for each were cloned into pBI771 behind the GAL4 TA domain and then transformed into GALA DB:NPRl-expressing yeast. The level of 
interaction was quantified with a $\beta$-gal assay of extracts prepared from yeast grown in liquid culture (Table 1). Since there was some variability from experiment to experiment in $\beta$-gal activity levels obtained with the same combination of prey and bait, 12 independent experiments were done. In addition, the levels of GAL4 TA:TGA and GAL4 BD:NPR1 fusion
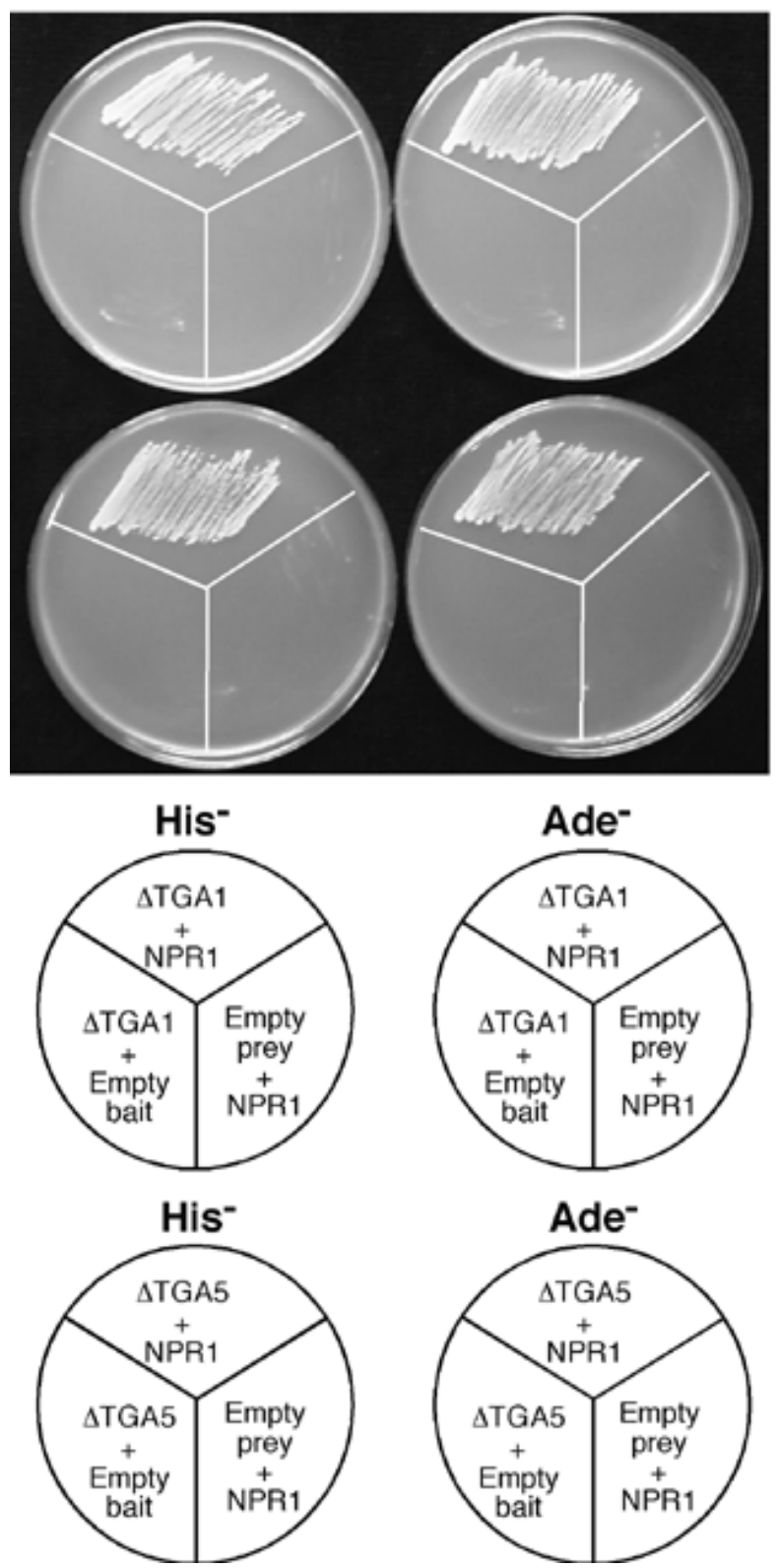

Fig. 1. Yeast two-hybrid assay of the interaction between NPR1 and truncated forms of TGA1 or TGA5. Yeast strain PJ69-4A containing combinations of NPR1 in the bait vector pBI880 and N-terminal- truncated forms of TGA1 $(\Delta \mathrm{TGA} 1)$ or TGA5 $(\Delta \mathrm{TGA} 5)$ in the prey vector $\mathrm{pBI771}$ were grown for 2 days at $30^{\circ} \mathrm{C}$ on synthetic dropout (SD) media lacking leucine (for maintenance of the bait vector), tryptophan (for maintenance of the prey vector), and histidine (His ${ }^{-}$) or adenine (Ade ${ }^{-}$) to allow detection of His 3 or Ade 2 reporter gene expression. $\triangle$ TGA1- or $\Delta$ TGA5-expressing PJ69-4A cells were unable to grow on $\mathrm{His}^{-}$or $\mathrm{Ade}^{-}$ media in the absence of NPR1 (empty bait vector). Similarly, NPR1expressing PJ69-4A cells were unable to multiply on $\mathrm{His}^{-}$and $\mathrm{Ade}^{-}$media in the absence of $\Delta$ TGA1 or $\Delta$ TGA5 (empty prey vector). proteins were monitored by immunoblot analysis for several experiments (see below).

Based on $\beta$-gal activity levels, TGA3 consistently showed very strong interaction with NPR1. The levels of $\beta$-gal activity even surpassed those of the p53/SV40 T antigen positive control. TGA2, while more variable, on average gave high levels of $\beta$-gal activity in the presence of NPR1. The interaction between NPR1 and either TGA5 or TGA6 was considerably weaker. In contrast, TGA1 and TGA4 exhibited little or no detectable interaction with NPR1, respectively.

To determine whether the marked difference in $\beta$-gal activity levels observed with the various TGA family members was due to differences in their affinity for NPR1 or to differences in their synthesis or stability in yeast, protein extracts were prepared from the same set of different yeast transformants in the same experiment used for $\beta$-gal activity determination. These protein extracts were subjected to immunoblot analysis. The results from one such experiment are shown in Figure 2A and B. Immunoblot analysis with antibodies to the GAL4 TA domain revealed that the TGA1, TGA2, TGA3, and TGA5 fusion proteins accumulated to similar levels in their respective transformed lines (Fig. 2A, left half). By contrast, the $\beta$ gal activity levels exhibited by these transformants ranged from 3.4 to $209.0 \mathrm{U}$ (Fig. 2C, left half). Since the levels of GAL4 DB:NPR1 were similar in all of the transformants (Fig. $2 \mathrm{~B}$, left half), the $\beta$-gal activity levels for TGA1, TGA2, TGA3, and TGA5 likely reflect the strength of their interaction with NPR1. In this particular experiment, only a very low

Table 1. Induction of $\beta$-galactosidase ( $\beta$-gal) activity with an NPR1 bait vector and various TGA family members as prey

\begin{tabular}{lcrccrc}
\hline Prey $^{\mathbf{a}}$ & Bait $^{\mathbf{b}}$ & Ave. $^{\mathbf{c}}$ & Range $^{\mathbf{c}}$ & Prey $^{\mathbf{d}}$ & Ave. $^{\mathbf{e}}$ & Range $^{\mathbf{e}}$ \\
\hline TGA1 & NPR1 & $2.7^{\mathrm{f}}$ & $1.0-4.1$ & $\Delta$ TGA1 & 6.8 & $3.1-20.6$ \\
TGA2 & NPR1 & 47.2 & $24.3-59.2$ & $\Delta$ TGA2 & 100.4 & $30.8-213.5$ \\
TGA3 & NPR1 & 153.3 & $74.2-238.4$ & $\Delta$ TGA3 & 32.9 & $21.1-43.1$ \\
TGA4 & NPR1 & 1.7 & $0.8-2.9$ & $\Delta$ TGA4 & 2.6 & $0.9-5.0$ \\
TGA5 & NPR1 & 17.2 & $6.4-31.8$ & $\Delta$ TGA5 & 28.5 & $5.4-78.9$ \\
TGA6 & NPR1 & 8.0 & $2.2-14.1$ & $\Delta$ TGA6 & 25.1 & $5.4-74.7$ \\
Empty prey & NPR1 & 1.1 & $1.0-1.2$ & $\Delta$ LTGA2 & 1.2 & $0.9-2.0$ \\
TGAs & $\begin{array}{c}\text { Empty } \\
\text { bait }^{1}\end{array}$ & 0.4 & $0.1-0.6$ & & & \\
p53 $^{\text {j }}$ & $\begin{array}{c}\text { SV40 T- } \\
\text { antigen }\end{array}$ & 65.2 & $31.9-115.2$ & & & \\
& & & & &
\end{tabular}

${ }^{\mathrm{a}}$ Prey vector with full-length TGA1-TGA6 cDNAs fused to the GAL4 TA domain.

${ }^{\mathrm{b}}$ Full-length NPR1 cDNA fused to GAL4 DB domain in the bait vector.

${ }^{c}$ Averages and ranges for TGA1-TGA6 with NPR1 were calculated from 12 independent experiments, with $\beta$-gal activity assayed in triplicate for each experiment.

${ }^{\mathrm{d}}$ Prey vector with N-terminal deletions of the TGAs (see Figure 3 for position of deletions) fused to the GAL4 TA domain, in combination with full-length NPR1 cDNA fused to the GAL4 DB domain in the bait vector.

${ }^{e}$ Average and range for $\Delta$ TGA1- $\Delta$ TGA6 with NPR1 were calculated from nine independent experiments, with $\beta$-gal activity assayed in triplicate for each experiment.

${ }^{f}$ One unit of $\beta$-gal activity is defined as the ability to produce 0.001 $A_{420}$ unit of ONPG degradation product by $1 A_{600}$ unit of yeast cells in 1 minute.

${ }^{\mathrm{g}}$ Prey vector without any insert.

${ }^{\mathrm{h}}$ Longer $\mathrm{N}-\mathrm{t}$ deletion, which extends the original deletion 46 aa beyond the leucine zipper region.

${ }^{\mathrm{i}}$ Bait vector without any insert.

${ }^{\mathrm{j}}$ The interaction between the viral oncogene product, SV40 T-antigen, and the classical tumor suppressor, p53, was used as a positive control. 
level of TGA6 fusion protein was detected. This is consistent with a lower $\beta$-gal activity $(6.0 \mathrm{U})$ than generally observed with this member (average $8.0 \mathrm{U}$, see Table 1). In other experiments in which TGA6 accumulated to levels equal to or higher than those of other family members, the corresponding $\beta$-gal activity was consistently lower than that for TGA2, TGA3, and TGA5 but higher than that for TGA1. Therefore, we suggest that these five TGAs differentially interact with NPR1, with the following order of apparent affinity: TGA3 > TGA2 > TGA5 > TGA6 > TGA1.

In contrast to the results obtained with TGA1, TGA2, TGA3, TGA5, and TGA6, the absence of $\beta$-gal activity above background for TGA4 is most likely due to a lack of detectable fusion protein. It is likely that this protein is unstable in yeast since it was cloned three separate times into the same prey vector as the other TGA family members. Moreover, the accuracy of the cloning, including the entire reading frame, was confirmed by DNA sequencing. (See below for a discussion of the instability of TGA factors and the potential biological significance of this phenomenon.)

\section{Influence of the N-t of different TGA factors} on their stability and ability to bind NPR1.

While truncated forms of TGA1 and TGA5 were identified as NIPs in the initial two-hybrid screen, their full-length forms exhibited rather weak (TGA5) or little interaction (TGA1) with NPR1 (Table 1). These results suggested that the N-t re- gion, which represents the least conserved portion of the different TGA members with respect to sequence and length (Xiang et al. 1997), may affect their stability and/or NPR1 binding. To test this possibility, N-t deletion mutants of the remaining four members were constructed and inserted into pBI771 (Fig. 3). Based on sequence similarity, the six members have been divided into three subfamilies (Xiang et al. 1997). TGA1 and TGA4 constitute the first subfamily; TGA2, TGA5 and TGA6 make up the second subfamily; and TGA3 constitutes the third. TGA2, TGA5, and TGA6 are considerably smaller than the other three members because they lack a 49 to 58 aa extension at their N-t (Xiang et al. 1997). To facilitate interpretation of the effects of removing the N-t on NPR1 binding, the deletions in TGA2 $(\Delta 1$ to 81 aa) and TGA6 ( $\Delta 1$ to 75 aa) were made at the same corresponding location as that found in the truncated TGA5 ( $\Delta 1$ to 75 aa) isolated in the two-hybrid screen. Similarly, the TGA4 deletion ( $\Delta 1$ to 135 aa) corresponded to that of the truncated form of TGA1 ( $\Delta 1$ to 139 aa). The TGA3 $N$-t deletion ( $\Delta 1$ to 153 aa) matched those of TGA1 and TGA4.

The quantitative $\beta$-gal assay was used to assess the interaction of NPR1 with the N-t-deleted forms of each TGA family member (right half of Table 1 and Figure 2C). The deleted forms of TGA1, TGA2, TGA4, TGA5, and TGA6 were observed to confer 1.5 - to threefold greater $\beta$-gal activity than their full-length counterparts. However, immunoblot analyses with antibodies against the GAL4 TA domain of the TGA fu-

A
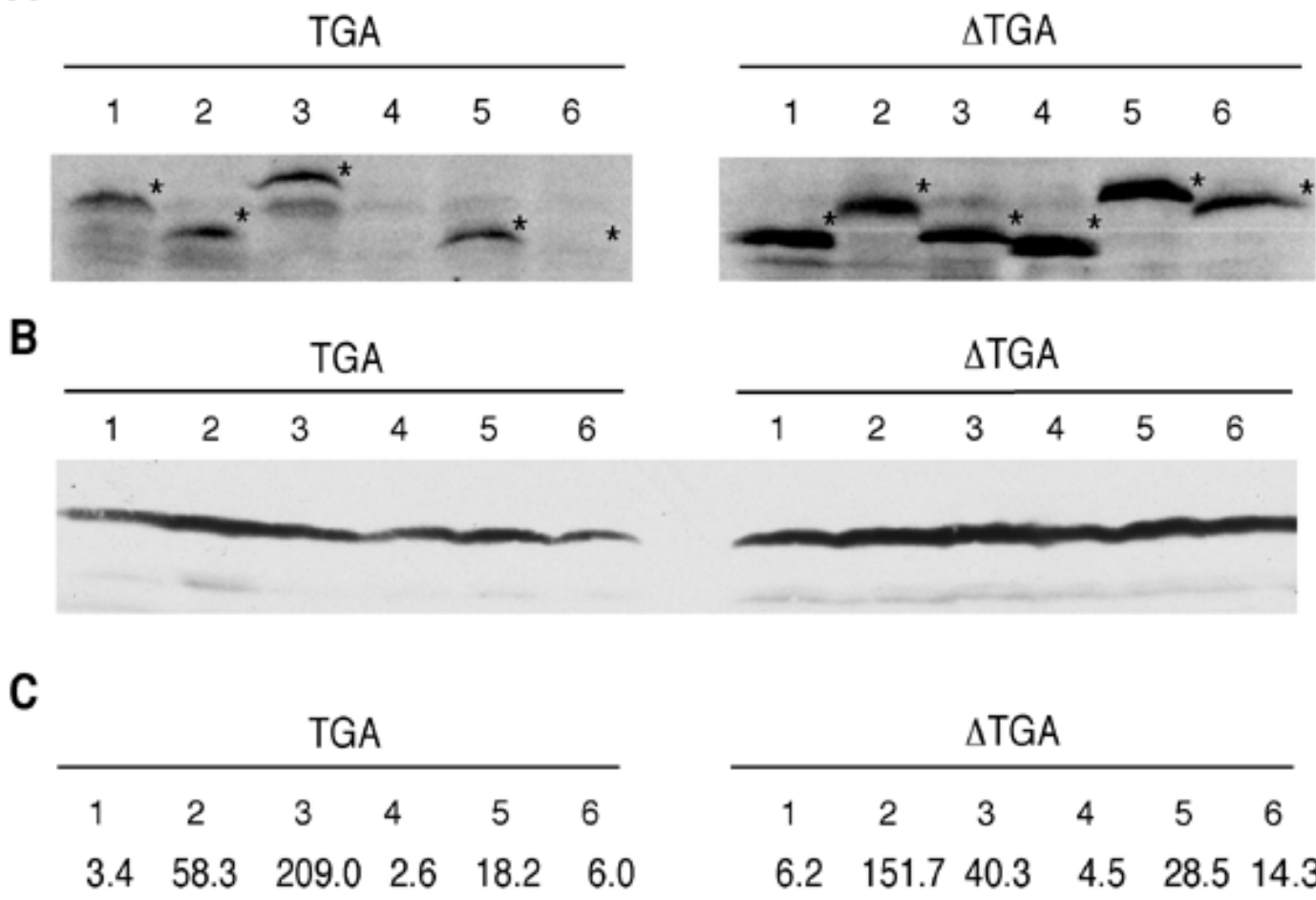

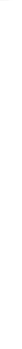


sion proteins (e.g., Fig. 2A, right half) or against the GAL4 DB domain of the NPR1 fusion protein (Fig. 2B, right half) reveal that the higher $\beta$-gal activity associated with the $\mathrm{N}$-tdeleted forms of TGA1, TGA2, TGA5, and TGA6 was likely due to increased protein levels. Interestingly, the truncated form of TGA4 was dramatically more stable than its fulllength form, yet it exhibited little interaction with NPR1. Unlike all of the other TGA members, removal of TGA3's N-t reduced the corresponding level of $\beta$-gal activity by approximately fivefold despite the greater abundance of the truncated form versus the full-length form (Fig. 2A and C, Table 1). Thus, this N-t appears to facilitate TGA3's interaction with NPR1. The above result therefore suggests that the N-t regions of TGA3 and the other TGA family members destabilize the proteins in yeast and positively affect TGA3's ability to interact with NPR1. Moreover, the truncated forms of these six factors also exhibited differential interaction with NPR1, with the following order of apparent affinity: $\Delta$ TGA2 > $\Delta$ TGA3, $\Delta$ TGA5, $\Delta$ TGA6 $>\Delta$ TGA $1>\Delta$ TGA4.

\section{Mapping the NPR1 binding site on the TGA factors.}

The N-t deletions in TGA2, TGA5, and TGA6 removed the basic DNA binding domain and half of the leucine zipper region, while those in TGA1, TGA3, and TGA4 removed all of these sequences plus an additional approximately 15 aa beyond the leucine zipper domain. A second set of deletions in TGA1, TGA3, and TGA4, which correspond in location to those in TGA2, TGA5, and TGA6, gave levels of $\beta$-gal activity similar to their corresponding truncated form with the larger deletion. This result suggests that the carboxy-terminal (C-t) half of the leucine zipper domain does not affect binding of NPR1 (data not shown). Since all of the deleted TGAs, ex- cept TGA4, retained their capacity to interact with NPR1, the major NPR1 interaction site must be $\mathrm{C}$-t to the leucine zipper domain. To help identify this binding site, a larger deletion was made in TGA2 and TGA6 that extended 46 or 47 aa beyond the leucine zipper region (Fig. 3). TGA2 and TGA6 were chosen since they showed high and intermediate binding affinity for NPR1, respectively, in the first set of truncation mutants that were analyzed. This larger deletion severely reduced the stability of the resultant proteins in yeast, compared with their truncated form with the shorter deletion or fulllength form, and gave only background levels of $\beta$-gal activity (data not shown). This instability therefore did not allow us to determine whether this 30 -aa region C-t to the leucine zipper domain, spanning residues 15 to 47 , is required for interaction with NPR1.

\section{Mapping the TGA binding region on NPR1.}

To determine the portion of NPR1 required for interaction with the various TGA family members, three deletion mutants of NPR 1 were constructed: $\Delta \mathrm{N}-\mathrm{t}$, in which aa 1 to 100 were deleted; $\Delta \mathrm{AR}$, in which part of the ankyrin repeat region between aa 265 and 373 was removed; and $\Delta \mathrm{AD}$, in which part of the acidic domain between aa 443 and 593 was deleted (Fig. 4A). These constructs were cloned into the bait vector pBI880 and tested for their ability to interact with full-length TGA2, TGA3, or TGA5 in the two-hybrid system with the quantitative $\beta$-gal assay (Fig. 4B). These particular TGA members were used because they exhibited the strongest interaction with full-length NPR1. Deletion of the ankyrin repeat region or the $\mathrm{C}-\mathrm{t}$ acidic region reduced $\beta$-gal activity to basal levels, initially suggesting that at least portions of both regions are required for TGA binding. Deletion of NPR1's N-t

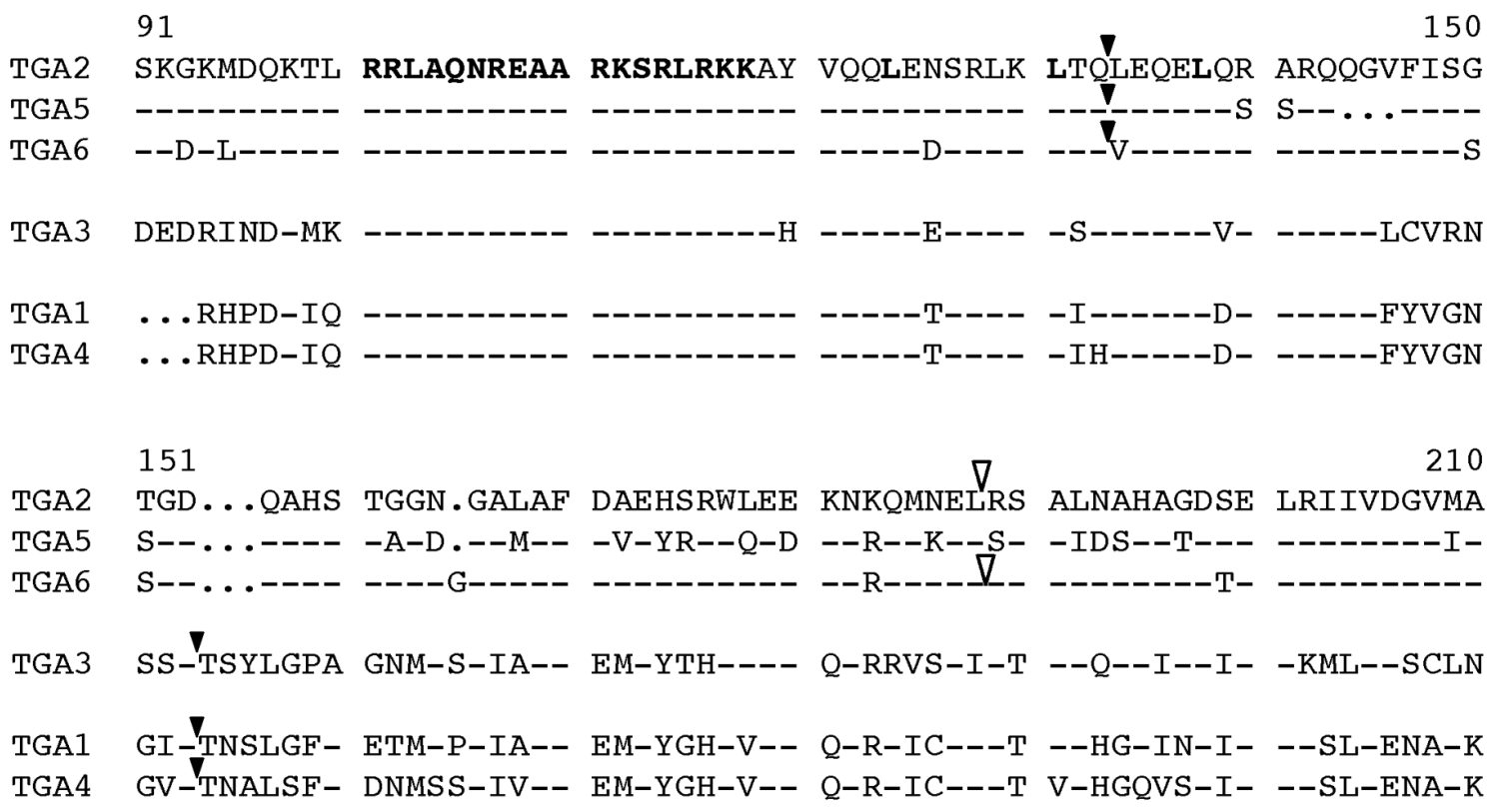

Fig. 3. Optimal amino acid alignment of the relevant portions of six members of the Arabidopsis TGA family of transcription factors and locations of the deletion points for the N-terminal (N-t)-truncated TGA factors. Nomenclature of Xiang et al. (1997) is used for this family of bZIP factors; numbering is based on TGA3, which is the largest family member due to a long N-t extension. The conserved basic DNA binding region and posit ions of leucine residues in the leucine zipper region are shown in bold in the TGA2 sequence. Identical residues are represented by dash lines. For optimal alignment, gaps were introduced by the PILEUP program; they are indicated by dots. All sequence analysis was conducted with the Wisconsin GCG package. Positions of the N-t deletions are indicated by closed arrowheads. Both short and long N-t deletions were constructed for TGA2 and TGA6. The longer deletions are indicated by open arrowheads. 
region dramatically reduced the high levels of $\beta$-gal activity observed with TGA2 and TGA3 to the weaker level associated with TGA5. Interestingly, removing NPR1's N-t region did not appear to further reduce its weaker interaction with TGA5.

To determine whether the different $\beta$-gal levels seen with the deleted forms of NPR1 resulted from changes in the affinity of the NPR 1 mutants for the various TGA family members or from differences in their synthesis or stability in yeast, a portion of the culture of the different yeast transformants used for $\beta$-gal activity determination was also subjected to immunoblot analysis with antibodies to the GAL4 DB domain (Fig. 4C). In four independent experiments, the GAL4

\section{A}

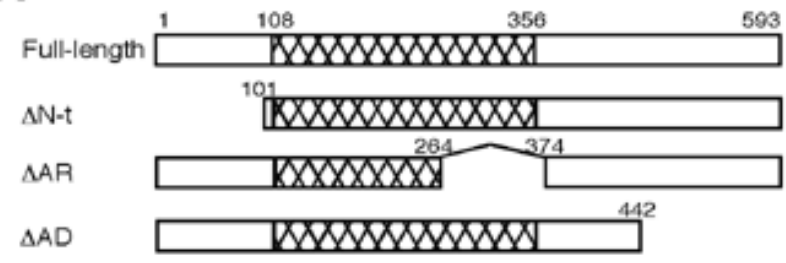

B

\begin{tabular}{|c|c|c|c|c|}
\hline \multirow[t]{2}{*}{ Prey } & \multicolumn{4}{|c|}{ Bait } \\
\hline & $\mathrm{FL}$ & $\Delta \mathrm{N}-\mathrm{t}$ & $\Delta \mathrm{AR}$ & $\Delta A D$ \\
\hline TGA2 & $68.5 \pm 1.7$ & $4.8 \pm 0.1$ & $1.2 \pm 0.1$ & $1.9 \pm 0.0$ \\
\hline TGA3 & $223.2 \pm 17.7$ & $6.0 \pm 0.1$ & $1.1 \pm 0.0$ & $0.5 \pm 0.0$ \\
\hline TGA5 & $8.1 \pm 0.2$ & $6.8 \pm 0.1$ & $0.9 \pm 0.0$ & $1.2 \pm 0.0$ \\
\hline Contro & $75.2 \pm 1.6$ & & & \\
\hline
\end{tabular}

C

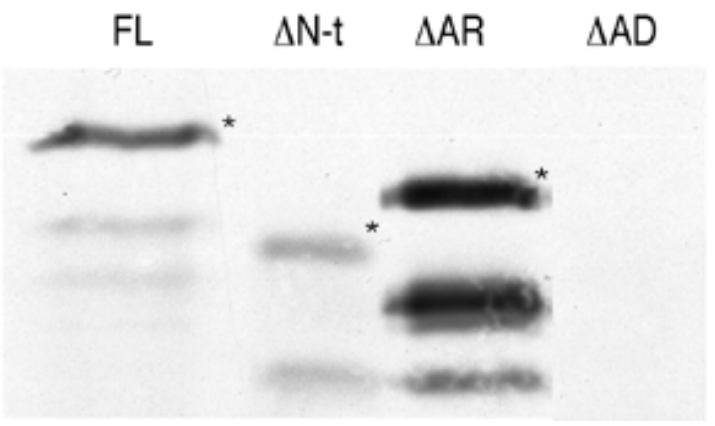

Fig. 4. Interaction between deletion mutants of NPR1 and several members of the TGA family. A, A schematic diagram of the full-length (FL) and deleted forms of NPR1. Three domains of NPR1 include the Nterminal (N-t; amino acids [aa] 1-107), ankyrin repeat region (AR; aa 108-355), and C-terminal (C-t) acidic domain (AD; aa 356-593). $\Delta \mathrm{N}-\mathrm{t}$ lacks the first 100 aa; $\triangle \mathrm{AR}$ is missing aa $265-373 ; \Delta \mathrm{AD}$ lacks aa 443 593. B, Levels of $\beta$-galactosidase ( $\beta$-gal) activity (units) in yeast transformants expressing various forms of NPR1 as bait and TGA2, TGA3, or TGA5 as prey. Control is P53/SV40 T-antigen. C, Immunoblot analysis of levels of NPR1 and its truncated forms in yeast transformants expressing TGA2 in the prey vector $\mathrm{pBI771}$ and various forms of NPR1 in the bait vector pBI880. NPR1 and its deleted forms were detected with an antibody against the GAL4 DB domain of the GAL4 DB:NPR1 fusion proteins. Bands corresponding to the undegraded fusion proteins are indicated by asterisks.
DB:NPR1 fusion protein containing the acidic domain deletion could not be detected. Thus, removing this region of NPR1 appears to lead to a dramatic loss of stability. The absence of detectable C-t truncated NPR1 in yeast presumably accounts for the very low $\beta$-gal activity; therefore, we were unable to assess whether the acidic domain is required for interaction with the TGA factors. In contrast, the ankyrin repeatdeleted GAL4 DB:NPR1 was repeatedly found to accumulate to much higher levels than the corresponding full-length protein. Therefore, the complete reduction in $\beta$-gal activity to basal levels caused by this deletion argues that the ankyrin repeat region is essential for interaction with the TGA factors. The amount of GAL4 DB:NPR1 containing the N-t deletion was somewhat variable when compared with the levels of the corresponding full-length protein in different experiments. Nonetheless, the N-t deletion consistently and dramatically reduced the strong interaction between this protein and TGA2

Table 2. Induction of $\beta$-galactosidase ( $\beta$-gal) activity by the interaction of TGA 2 or TGA3 with wild-type or mutant NPR1 proteins

\begin{tabular}{lcrrr}
\hline & \multirow{2}{*}{$\begin{array}{c}\text { Amino acid } \\
\text { Mutant }\end{array}$} & \multirow{2}{*}{$\begin{array}{c}\text { Clone } \\
\text { alternation }\end{array}$} & & \multicolumn{2}{c}{$\beta$-gal activity (units) } \\
\cline { 5 - 6 } no. & & TGA2 & TGA3 \\
\hline NPR1 & Wild type & & $23.41 \pm 0.29$ & $61.43 \pm 0.89$ \\
npr1-2 & C150 $\rightarrow \mathrm{Y}$ & 21 & $0.22 \pm 0.00$ & $0.39 \pm 0.02$ \\
& & 23 & $0.27 \pm 0.00$ & $0.58 \pm 0.01$ \\
& & 24 & $0.26 \pm 0.02$ & $0.52 \pm 0.01$ \\
nim1-2 & $\mathrm{H} 300 \rightarrow \mathrm{Y}$ & 33 & $0.41 \pm 0.01$ & $0.94 \pm 0.15$ \\
& & 34 & $0.28 \pm 0.01$ & $0.59 \pm 0.01$ \\
npr1-1 & $\mathrm{H} 334 \rightarrow \mathrm{Y}$ & 41 & $0.23 \pm 0.02$ & $0.65 \pm 0.02$ \\
& & 42 & $0.41 \pm 0.02$ & $0.71 \pm 0.01$ \\
& & 43 & $0.33 \pm 0.02$ & $0.62 \pm 0.00$ \\
npr1-5 & $\mathrm{P} 342 \rightarrow \mathrm{S}$ & 51 & $0.30 \pm 0.02$ & $0.61 \pm 0.02$ \\
& & 52 & $0.22 \pm 0.02$ & $0.75 \pm 0.01$ \\
& & 53 & $0.26 \pm 0.02$ & $0.65 \pm 0.01$ \\
\hline
\end{tabular}

${ }^{a}$ Residue number of the amino acid mutated in NPR1 and its alternation for each mutant are given.

${ }^{b}$ Point mutations corresponding to each of the four npr1 mutants were introduced by polymerase chain reaction into the pBI880-NPR1 bait vector and two or three clones for each mutant (after DNA sequence confirmation) were analyzed in parallel for $\beta$-gal activity in yeast strain PJ69-4A expressing either TGA2 or TGA3 in the prey vector.

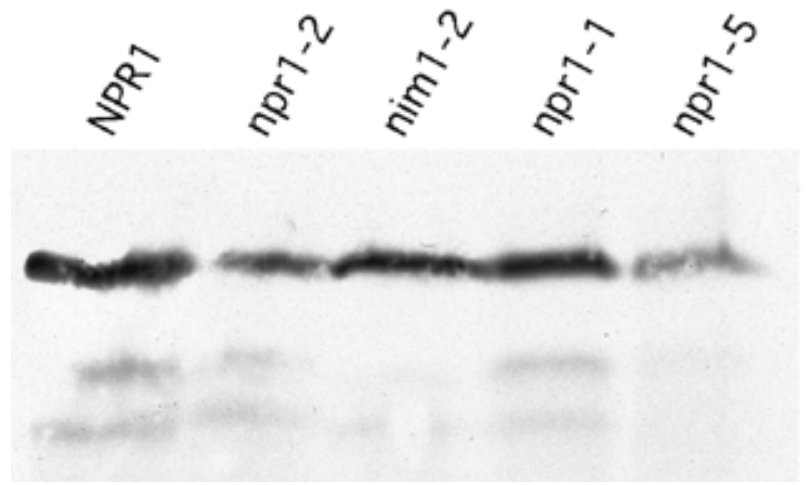

Fig. 5. Immunoblot analysis of NPR1 and its mutant forms in yeast. Total protein from yeast strain PJ69-4A expressing TGA3 in prey vector pBI771 and either wild-type or mutant NPR1 fused to the GAL4 DB domain in bait vector pBI880 were fractionated by electrophoresis on a $15 \%$ sodium dodecyl sulfate-polyacrylamide gel (SDS-PAG) and then subjected to immunoblot analysis with antibodies against the GAL4 DB domain. Analysis of total proteins from PJ69-4A cells expressing wildtype or mutant NPR1 plus TGA2, instead of TGA3, gave similar results. 
or TGA3, but had little effect on its weaker binding to TGA5. Thus, we conclude that the ankyrin repeats are essential for NPR1's interaction with the TGA factors while the N-t domain, although dispensable, facilitates a strong interaction with certain TGA family members.

\section{Four npr1 point mutations known to disrupt SA signaling in Arabidopsis also prevent interaction with TGA2 and TGA3.}

To determine whether the interaction between NPR1 and the TGA factors observed in yeast is relevant to NPR1's function in Arabidopsis, four nprl point mutants (nprl-1, nprl-2, npr1-5 [formerly sail-1], and nim1-2), which result in loss of responsiveness to $\mathrm{SA}$ and its synthetic functional analogues INA and BTH in Arabidopsis (Cao et al. 1994; Delaney et al. 1995; Glazebrook et al. 1996; Shah et al. 1997) were tested for their ability to interact with full-length TGA2 and TGA3 in the yeast two-hybrid system. Point mutations corresponding to each of the mutants were introduced by polymerase chain reaction (PCR) into the pBI880-NPRl bait vector. Three clones of each mutant were sequenced to verify that the expected mutation had been created and then all were analyzed in parallel for $\beta$-gal activity in yeast strain PJ69-4A carrying either the TGA 2 or TGA3 prey vector (Table 2). All four point mutations were observed to completely suppress $\beta$-gal activity to basal levels, implying that they destroy NPR1's ability to interact with either of these TGA factors. Immunoblot analysis with the GAL4 DB antibodies demonstrated that nim1-2 and npr1-1 were present at levels similar to that of the wild-type protein in yeast extracts prepared in parallel with those used for the $\beta$-gal assay (Fig. 5). In addition, though the levels of npr1-2 and npr1-5 appeared to be a few fold lower than that of wild-type NPR1, this modest reduction cannot account for the complete suppression of $\beta$-gal activity to basal levels. Therefore, we conclude that all four $n p r l$ point mutations known to disrupt SA signaling in planta also prevent NPR1 from interacting with several TGA family members in yeast. Furthermore, since all four mutations are in the ankyrin repeat region, these results provide further evidence that this region is critical for binding the TGA factors.

\section{TGA2 and TGA3 bind the TGACG element of the} Arabidopsis $P R-1$ promoter required for SA inducibility.

NPR1 is required for the induction of Arabidopsis $P R-1$ expression by SA and its two functional analogues, INA and BTH (Cao et al. 1994; Delaney et al. 1995; Glazebrook et al.

Fig. 6. Binding of TGA2 and TGA 3 to the TGACG-containing fragment of the $P R-1$ promoter. A 22-bp oligonucleotide (L7) corresponding to the -640 region of the $P R-1$ promoter, which contains the TGACG element and is required for salicylic acid (SA)/2,6-dichloroisonicotinic acid (INA) inducibility (Lebel et al. 1998), or a mutated version (M-L7), which alters the TGACG element and destroys responsiveness to SA/INA (Lebel et al. 1998), were used as probes. Recombinant (A) TGA2 and (B) TGA3 were incubated with labeled L7 (lane 2) or M-L7 probe (lane 12) and then subjected to gel-retardation analyses. Specificity of TGA2 and TGA3 binding to the labeled L7 probe was assessed by addition of increasing amounts of excess unlabeled L7 (lanes 3-5), ML7 (lanes 6-8), and lower (lane 9) or upper (lane 10) strand of the L7 probe. Molar excess for each competition assay is indicated. FP indicates position of the free probe.
1996; Shah et al. 1997). Recently, linker-scanning mutational analysis of the promoter for this gene demonstrated that a region highly homologous to the recognition sites for bZIP transcription factors is essential for $P R-1$ activation by SA and INA in planta (Lebel et al. 1998). Moreover, INA treatment was found to alter the in vivo footprint over this region, which is centered at -640 from the transcriptional start site.

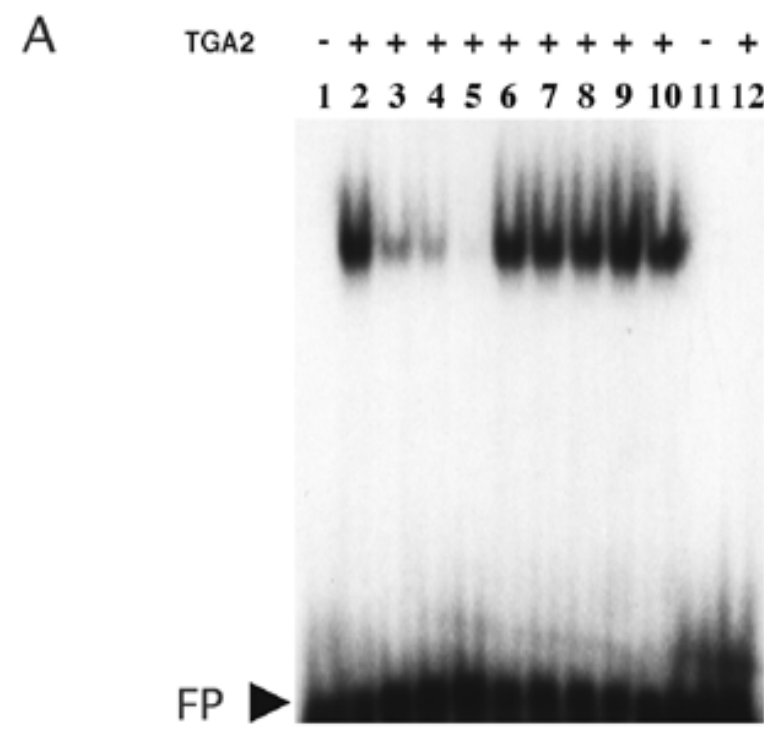

B

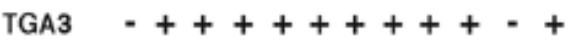

123456789101112

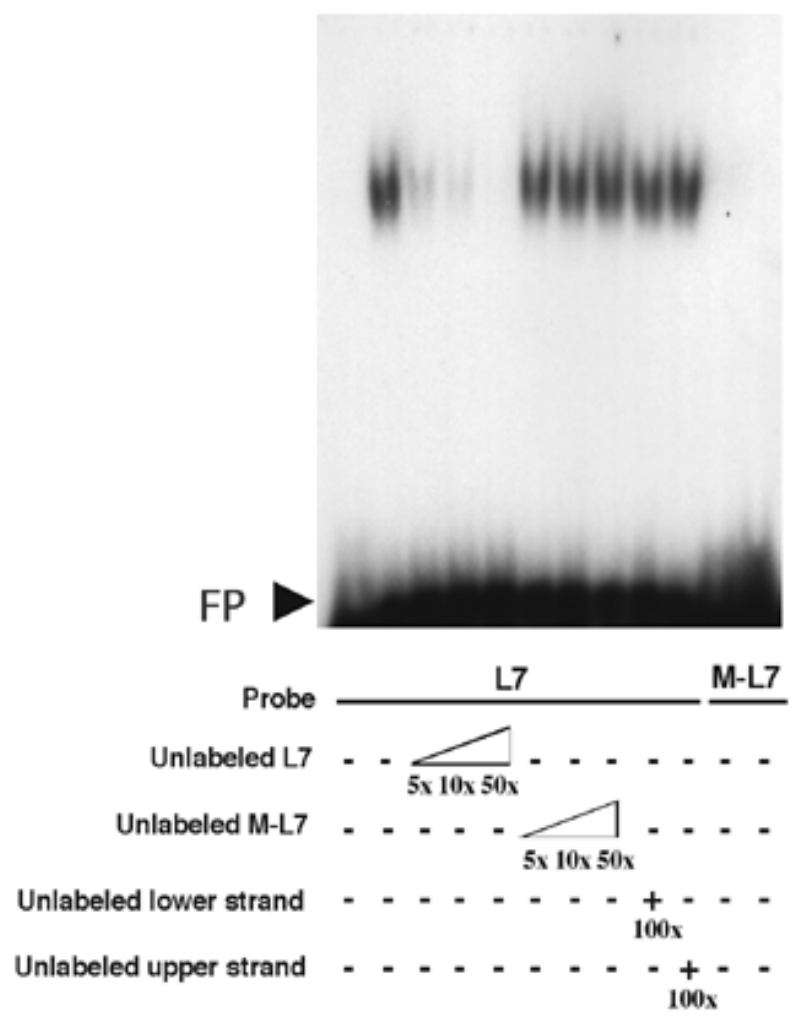


To determine whether this SA- and INA-responsive region containing a TGACG element was recognized by various TGA factors, gel-retardation analysis was performed. Both TGA 2 and TGA3, the two family members that strongly interact with NPR1, were observed to bind a 22-bp oligonucleotide (LS7) derived from this region (Fig. 6A and B, lane 2). Moreover, this binding was specific. TGA2 and TG3 failed to bind a mutated form of this oligonucleotide (M-LS7) corresponding to the linker-scanning mutation that disrupted the TGACG element and eliminated SA and INA inducibility of a reporter gene (Lebel et al. 1998; Fig. 6A and B, lane 12). Furthermore, binding to labeled LS7 was suppressed by a five- to 50-fold molar excess of unlabeled LS7 but not unlabeled M-LS7 (Fig. 6A and B, lanes 2-8). Therefore, TGA2 and TGA 3 bind an element of the $P R-1$ promoter as well as NPR1; these are both required for SA-mediated induction of $P R-1$ expression.

\section{DISCUSSION}

Genetic analyses have identified NPR1 as a critical component that functions downstream of SA in the disease resistance signal transduction pathway leading to the activation of defense genes, such as $P R-1$. To uncover proteins that physically interact with NPR1 (NIPs), we used the yeast two-hybrid system. Three distinct classes of NIPs were identified. Interestingly, one of these classes was composed of truncated forms of two members of the Arabidopsis TGA/OBF transcription factor family. Previous studies have implicated these factors in the activation of various SA-induced genes, including $P R-1$.

\section{NPR1 differentially interacts with six members of the TGA family.}

Using the yeast two-hybrid system, we assessed the ability of six characterized members of this transcription factor family to interact with NPR1. TGA3 appeared to have the highest affinity for NPR1, while the apparent affinities of TGA2, TGA5, and TGA6 for NPR1 were lower. Of the latter three proteins, TGA2 showed the highest apparent affinity for NPR1 and TGA6 exhibited the lowest. By contrast, TGA1 appeared to interact with NPR1 only very weakly and TGA4 did not accumulate to detectable levels based on immunoblot analysis; thus, its interaction with NPR1 could not be addressed.

The different apparent affinities exhibited by the various TGA family members for NPR1 roughly corresponded to their division into three subfamilies, based on sequence similarity (Xiang et al. 1997). TGA3, which showed the highest level of interaction with NPR1, constitutes its own subfamily because it shares less than $65 \%$ DNA sequence homology with the other TGA members. TGA2, TGA5, and TGA6, which exhibited a more modest apparent affinity for NPR1, form the second subfamily, as they share 82.1 to $85 \%$ DNA sequence homology and 92.8 to $95.3 \%$ aa similarity. Lastly, TGA1 and TGA4, which are $81.6 \%$ homologous at the DNA sequence level and $92.0 \%$ similar at the amino acid level, compose the third subfamily. TGA1 exhibited little interaction with NPR1.

Using a similar approach, Zhang et al. (1999) recently reported that NPR1 interacts strongly with TGA2 (AHBP-1b) and TGA6 and very weakly with TGA5 (OBF5). These results differ somewhat from ours. A likely explanation for this discrepancy is that the levels of the various TGAs may not be consistent in their yeast two-hybrid system. Based on immunoblot analysis, we found that accumulation of the different TGA members can vary significantly (e.g., Fig. 2A). Thus, extrapolation of interaction strength from $\beta$-gal activity levels must be interpreted cautiously with the levels of the expressed proteins taken into consideration.

\section{The N-t of the different TGA factors affect their stability and affinity for NPR1.}

Interestingly, in both our two-hybrid screen and that of Zhang et al. (1999), only N-t-truncated forms of this family of bZIP factors were obtained from Arabidopsis (TGA1 and TGA5) and tomato (NIF1). These results could reflect inefficiencies in the construction of full-length cDNAs during preparation of the prey libraries; however, it is also possible that the $\mathrm{N}-\mathrm{t}$ of these factors affect their stability in yeast and/or their ability to bind NPR1. To assess these possibilities, $\mathrm{N}-\mathrm{t}$ deletions were constructed in the remaining four Arabidopsis TGA members such that the truncated forms matched the corresponding subfamily member obtained in the twohybrid screen. Increased levels of $\beta$-gal activity were seen with the truncated versus full-length forms of TGA1, TGA2, TGA5, and TGA6 (Table 1, Fig. 2C). However, the heightened $\beta$-gal activity was likely due to a corresponding increase in the levels of the $\mathrm{N}$-t-deleted proteins. While removal of the $\mathrm{N}-\mathrm{t}$ of TGA4 greatly increased its stability, the truncated TGA4 still exhibited little interaction with NPR1. Since removal of the N-t region from TGA1 (which is highly similar to that of TGA4) did not adversely affect its ability to bind NPR1, the full-length TGA4, even if stable, would likely have little affinity for NPR1.

Unlike the other TGA factors, loss of the N-t of TGA3 resulted in a large decrease in $\beta$-gal activity, despite the heightened accumulation of the truncated protein, compared with the full-length form. This result suggests that TGA3's N-t, which is approximately 50 to 60 aa longer than those of TGA2, TGA5, and TGA6 and significantly divergent from those of TGA1 and TGA4, positively contributes to this factor's ability to bind NPR1. In addition, the observation that the N-t-deleted forms of all six TGA factors accumulated to several-fold higher levels than their full-length counterparts suggests that the $\mathrm{N}$-t of these proteins reduce their stability in yeast.

The truncated forms of the different TGA factors retained their ability to bind to NPR1 despite the complete removal of their basic DNA binding domains and either partial (TGA2, TGA5, and TGA6) or complete (TGA1, TGA3, and TGA4) removal of their leucine zipper domains. Thus, the NPR1 binding site appears to lie C-terminal to the leucine zipper domain. Deleting an additional 46 or 47 aa beyond the leucine zipper region in TGA2 and TGA6 resulted in loss of detectable TAG 2 or TGA6 protein and $\beta$-gal activity, suggesting that this region is necessary for stability in yeast.

Leucine zippers are required for formation of hetero- or homodimers of bZIP factors. The observation that the truncated forms bind NPR1 despite partial or complete loss of this motif indicates that the TGA factors can interact with NPR1 in their monomeric form. It is currently unknown whether dimerization affects NPR1 binding. However, the different TGA factors have been shown to form heterodimers as well as 
homodimers in vitro, which raises the possibility of forming 21 distinct dimers from the six members discussed in this study (Meisel and Lam 1997). Therefore, if TGA dimers bind NPR1, the N-t of one member of the heterodimer might also affect the ability of the other member to interact with NPR1. In this scenario, the ability of these six TGA members to differentially interact with NPR1 in either homodimeric or heterodimeric forms would provide a complex mechanism through which the activity of this family of transcription factors could be regulated by SA via NPR1.

Processing of the TGA factors may also serve as a mechanism for regulating their availability to interact with NPR1. The cloning of only $\mathrm{N}$-t-truncated forms of TGAs from several cDNA libraries, in conjunction with the increased stability of these truncated forms in yeast, suggests that such forms could have biological significance in plants. Indeed, truncated versions of TGA:green fluorescent protein (GFP) fusions have been detected in mature leaves of transgenic plants. Significant accumulation of the full-length form of TGA1:GFP was detected only in young leaves and seedlings (D. Pontier and E. Lam, unpublished results).

\section{The TGA binding region of NPR1.}

The TGA binding region of NPR1 was partially mapped with three large deletions that removed either the $\mathrm{N}$-t region (aa 1 to 100), part of the ankyrin repeat region (aa 265 to 373), or the C-t acidic domain (aa 443 to 593). Removal of the acidic domain resulted in the absence of detectable NPR1, suggesting that this region is required for stability in yeast (Fig. 4). Deletion of part of the ankyrin repeat region led to a complete loss of $\beta$-gal activity in the two-hybrid system. Since this ankyrin repeat-defective protein accumulated to higher levels than the full-length NPR1, the lack of $\beta$-gal activity must reflect the inability of the truncated protein to interact with the TGA factors. The N-t deletion of NPR1 also affected $\beta$-gal activity. In a two-hybrid analysis with this mutant and either TGA2 or TGA3, $\beta$-gal activity was reduced to the low level previously detected with TGA5 and full-length NPR1. Interestingly, the N-t deletion did not affect NPR1's weak interaction with TGA5. Together, these results suggest that at least part of the TGA binding site is located in the ankyrin repeat region.

The involvement of the ankyrin repeat region in binding TGA was anticipated since ankyrin repeats are known to facilitate protein-protein interaction (e.g., Gorina and Pevletich 1996; Krappmann et al. 1996) and most of the mutations known to disrupt NPR1 function are located in this portion of the protein (Cao et al. 1997; Ryals et al. 1997; H. Cao, J. Shah, D. F. Klessig, and X. Dong, unpublished results). Our results also argue that the N-t region of NPR1 can enhance the interaction with some (TGA2 and TGA3) but not other (TGA5) family members. Thus, it appears that the N-t regions of both partners provide specificity to the interaction.

\section{Biological significance of NPR1's interaction with TGA factors in the yeast two-hybrid system.}

Three approaches were used to demonstrate that the NPR1TGA interactions detected in yeast are biologically significant. First, four independent nprl point mutations that disrupt SA signaling in Arabidopsis were found to prevent binding of the mutant proteins to TGA2 and TGA3 in the two-hybrid system
(Table 2). Interestingly, these point mutations are in the ankyrin repeat region; therefore, they provide further evidence that the TGA binding site of NPR1 is located in this domain. Second, TGA2 and TGA3 were observed to bind the TGACG element of the Arabidopsis $P R-1$ promoter in vitro (Fig. 6). This element was recently shown to be essential for SA and INA inducibility in planta (Lebel et al. 1998). Moreover, a mutation in this element known to disrupt SA/INA responsiveness in planta (Lebel et al. 1998) inhibited TGA2 and TGA3 binding in vitro (Fig. 6). Third, we attempted to demonstrate that recombinant NPR1 and TGA3 (and TGA2) produced in Escherichia coli physically interact in vitro. However, neither coimmunoprecipitation experiments with antibodies against NPR1 or TGA3 (or TGA2) or "pull-down" experiments with His- or glutathione S-transferase (GST)tagged recombinant proteins were successful. In contrast, Zhang et al. (1999) demonstrated physical interaction of NPR1 with both TGA2 and TGA5 in vitro with a similar "pull-down" experiment. The only significant difference between these experiments appears to be the source of the recombinant NPR1; they produced it in insect cells with a baculovirus vector, while we synthesized it in E. coli. While most of the NPR1 produced in E. coli was insoluble, only the soluble fraction of this protein was used for either coimmunoprecipitation or "pull- down" experiments. Moreover, in addition to TGA2, we utilized TGA3 while they used TGA5. However, based on $\beta$-gal activity assays, TGA3 appeared to have a far greater affinity for NPR1 than TGA5. These results suggest that one or more posttranslation modifications of NPR1, which presumably can occur in insect cells but not in E. coli, are necessary for its interaction with TGA family members.

\section{Comparison of NPR1 and I $\kappa B$.}

In addition to the ankyrin repeats, NPR 1 also shares limited overall sequence homology to IKB $\alpha$ (Ryals et al. 1997). In animals, members of the I $\mathrm{KB}$ family of inhibitors bind to members of the NF- $\kappa \mathrm{B} /$ Rel family of dimeric transcription factors. This binding prevents the NF- $\mathrm{KB} / \mathrm{Rel}$ factors from migrating to the nucleus and activating genes associated with innate and acquired immunity and inflammation. In response to various stimuli, such as a bacterial infection, I $\mathrm{kB}$ is phosphorylated; this targets the I $\mathrm{KB}: \mathrm{NF}-\kappa \mathrm{B}$ complex to the $26 \mathrm{~S}$ proteasome for degradation of I $\kappa \mathrm{B}$ and release of active NFKB (Baeuerle and Baltimore 1996; Whiteside and Israël 1997).

Despite the similarity to I $\mathrm{KB} \alpha$, previous studies have argued that NPR1 acts as a positive regulator of defense responses in plants. Its disruption blocks the expression of $P R$ genes and results in increased susceptibility to pathogens (Cao et al. 1994; Delaney et al. 1995; Glazebrook et al. 1996; Shah et al. 1997), while its overexpression leads to greater $P R$ gene expression after pathogen attack and enhanced resistance (Cao et al. 1997, 1998). The results presented in this paper further distinguish NPR1 from other I $\mathrm{KB}$ factors. We demonstrate that, rather than (or perhaps in addition to) binding to members of the NF- $\kappa \mathrm{B} /$ Rel family, NPR1 interacts with members of the TGA family of bZIP transcription factors. Whether NPR1 interacts with other plant transcription factors including a possible NF- $\mathrm{KB} / \mathrm{Rel}$ ortholog has not yet been demonstrated. However, the observation that induction of enhanced resis- 
tance to the pathogenic bacterium Pseudomonas syringae pv. tomato by the nonpathogenic rhizobacterium $P$. fluorescens requires NPR1 but is ethylene and jasmonic acid dependent and SA independent (Pieterse et al. 1998) argues that NPR1 plays a role in several defense signaling pathways. Therefore, it seems likely that NPR1 interacts with more than one family of transcription factors.

\section{The TGA factors link NPR1 to expression of the SA-responsive $P R-1$ gene.}

We have demonstrated that the critical SA signaling component NPR1 interacts with several TGA family members, including TGA2 and TGA3 (Table 1). In addition, point mutations in NPR1 that disrupt SA activation of $P R-1$ in Arabidopsis were shown to prevent NPR1 from binding to TGA2 and TGA 3 in yeast (Table 2). Furthermore, TGA2 and TGA3 were found to specifically bind the SA-responsive TGACG element of the Arabidopsis $P R-1$ promoter (Figure 6). Together, these observations establish a direct link between NPR1 and $P R-1$ gene expression via the TGA family of transcription factors. In addition, the differential interaction of TGA family members with NPR1 demonstrated here may provide a mechanism for the intricate and complex control of NPR1-dependent genes. The ability of truncated TGA factors to interact with NPR1 in yeast and the observation that TGA:GFP fusions are proteolytically processed in transgenic Arabidopsis and tobacco also raises the possibility that protein modification plays an important role in regulating the activities of this family of transcription factors. Finally, whether each member of the TGA family mediates different biological responses is an interesting question that remains unanswered. Although a dimeric type of TGA factor binding site has been shown to respond to auxins, jasmonate and SA (Xiang et al. 1996), it is not known whether each member of the TGA family has distinct or overlapping functions. Our comprehensive analysis of the interaction between NPR1 and six different TGA factors revealed significant differential behavior among these closely related proteins. This observation suggests that only a subset of the TGA factors are involved in the activation of SA-responsive genes via interaction with NPR1.

\section{MATERIALS AND METHODS}

\section{Strains and plasmids.}

Yeast strain PJ69-4A, in which three reporter genes (His3, $A d e 2$, and $L a c Z$ ) were integrated into the yeast chromosomes, was obtained from James et al. (1996). The prey library, containing cDNAs generated from Arabidopsis thaliana ecotype Columbia cloned behind the GAL4 TA domain in prey vector pBI771, was kindly provided by William Crosby (Wang et al. 1997).

An NPR1 cDNA was isolated from a cDNA library generated from RNA of Turnip crinkle virus-infected Arabidopsis thaliana Di-17 leaves. A SalI site and a NotI site were introduced by PCR into the $5^{\prime}$ and $3^{\prime}$ ends of the cDNA fragment. The resulting PCR product was sequenced from both ends extending to the SpeI and BsmFI site and cloned into pBluescript KS(II). The SpeI and BsmFI fragment of the PCR product was then replaced by the same fragment from DNA isolated from the cDNA library. The entire swapped open reading frame subsequently was cloned in-frame behind the
GAL4 DB domain into the SalI-NotI sites of bait vector pBI880. A C-t 131-aa deletion was made from full-length NPR1 by partial XhoI digestion and cloned back into pBI880. Also, an N-t 100-aa deletion was made by PCR and cloned into pBI880. A 109-aa fragment, encompassing aa 265 to 373 of the ankyrin repeat region, was deleted from the full-length NPR1 by an overlap PCR method (Ho et al. 1989).

The open reading frames of TGA1-TGA6 were cloned into pBI771 from previously described cDNAs (Xiang et al. 1997) as follows. cDNAs containing TGA1-TGA5 were digested by BamHI and NotI and cloned into BglII and NotI sites in pBI771 behind the GAL4 TA domain. TGA6 was cloned into EcoRI and NotI sites by PCR followed by sequencing to confirm the fidelity of the PCR. The PCR method also was used to clone TGA4 into pBI771 followed by sequencing. $\mathrm{N}$-t deletions $(\Delta)$ of TGA2, TGA4, and TGA6 and long N-t deletions $(\Delta \mathrm{L})$ of TGA 2 and TGA6 were cloned by PCR followed by sequencing. An SpeI-NotI fragment of TGA3 was cloned into pBI771 to form its N-t deletion.

\section{Yeast two-hybrid screening.}

The bait vector pBI880 harboring the in-frame NPR1 cDNA and containing the Leu2 selectable marker was first introduced into PJ69-4A. Then the Arabidopsis cDNA library in prey vector pBI771, which contains the Trp1 selectable marker, was transformed into the GAL4 DB:NPRl-expressing PJ69-4A by the method of Gietz et al. (1995). Transformants were plated on synthetic dropout (SD) medium lacking leucine $\left(\mathrm{Leu}^{-}\right)$, tryptophan $\left(\mathrm{Trp}^{-}\right)$and histidine $\left(\mathrm{His}^{-}\right)$. His ${ }^{+}$ positive clones from the first round of screening were replated on both SD $\mathrm{Leu}^{-} \mathrm{Trp}^{-} \mathrm{His}^{-}$or SD $\mathrm{Leu}^{-} \mathrm{Trp}^{-} \mathrm{Ade}^{-}$media. Those clones able to grow on both selective media were then grown in liquid culture and subjected to a $\beta$-gal assay. The positive clones were further confirmed by plasmid rescue and retransformation (Hoffman 1994). Only those retaining the phenotype were considered true positives.

\section{$\beta$-Galactosidase assay and immunoblot analyses.}

Single colonies were inoculated into $5 \mathrm{ml}$ of SD $\mathrm{Leu}^{-}$Trp liquid medium and grown at $30^{\circ} \mathrm{C}$ for 2 days. The 5-ml cultures were then transferred to $12.5 \mathrm{ml}$ of YPD (yeast extract, peptone, dextrose) liquid medium and allowed to grow for 3 to $5 \mathrm{~h}$ until they reached $\mathrm{OD}_{600} 0.7$ to 1.0 . The $\mathrm{OD}_{600} \mathrm{~s}$ were recorded. Three 1.5-ml aliquots were transferred into three 1.5$\mathrm{ml}$ Eppendorf tubes. The cells were harvested by centrifugation for $2 \mathrm{~min}$ in the microfuge at $4^{\circ} \mathrm{C}$ and washed one time with $1.5 \mathrm{ml}$ of room temperature $\mathrm{Z}$ buffer $\left(60 \mathrm{mM} \mathrm{NaHPO}_{4}\right.$, $\left.40 \mathrm{mM} \mathrm{NaH} \mathrm{PO}_{4}, 10 \mathrm{mM} \mathrm{KCl}, 1 \mathrm{mM} \mathrm{MgSO} 4\right)$. The cells were then resuspended in $100 \mu \mathrm{l}$ of $\mathrm{Z}$ buffer and were frozen and thawed three times in liquid nitrogen and $37^{\circ} \mathrm{C}$ water bath. $\mathrm{Z}$ buffer $(0.7 \mathrm{ml})$ with $\beta$-mercaptoethanol $(270 \mu \mathrm{l}$ per $100 \mathrm{ml}$ of $\mathrm{Z}$ buffer) was added to each tube. $O$-Nitrophenyl $\beta$ D-galactopyranoside (ONPG; $160 \mu \mathrm{l} ; 4 \mathrm{mg} / \mathrm{ml}$ ) was added to each tube and the reaction was allowed to proceed at $30^{\circ} \mathrm{C}$ until a yellow color developed, at which time the reaction was stopped by addition of $0.4 \mathrm{ml}$ of $1 \mathrm{M} \mathrm{Na}_{2} \mathrm{CO}_{3}$. The reaction time (from addition of ONPG to addition of $\mathrm{Na}_{2} \mathrm{CO}_{3}$ ) for each sample was recorded. The amount of ONPG degradation product was measured at $\mathrm{OD}_{420}$. The $\beta$-gal activity (in units) was calculated with the formula $1,000 \times A_{420} / 1.5 \times$ time $\times$ $A_{600}$. 
The remaining $13 \mathrm{ml}$ of cell culture was used for immunoblot analysis. Monoclonal antibodies to the GAL4 DB domain or to the GAL4 TA domain (Clontech, Palo Alto, CA) were used to detect the GAL4 DB:NPR1 fusion protein and GAL4 TA:TGA fusion proteins, respectively. Protein isolation and immunoblot analyses were done following instructions in the Clontech manual.

\section{Site-directed mutagenesis of NPR1.}

Point mutations corresponding to the nprl-1, nprl-2, nprl-5 (sail-1), and nim1-2 mutants were introduced into the pBI880-NPRI bait vector with the QuikChange Site-Directed Mutagenesis Kit and the instructions provided by the manufacturer (Stratagene, La Jolla, CA). Each plasmid was sequenced to confirm the presence of the point mutation and cotransformed with the pBI771-TGA2 or pBI771-TGA3 into PJ69-4A to monitor $\beta$-gal activity and levels of wild-type and mutant NPR1.

\section{Expression of recombinant TGA2 and TGA3 and gel-retardation assay.}

The coding region of TGA 2 and TGA3 was cloned into the pET28a (Novagen, Madison, WI). His-tagged proteins were expressed in BL21 (DE3) cells and purified to near homogeneity on Ni-NTA-agarose columns according to the manufacturer's instructions (Qiagen, Valencia, CA).

A 22-bp oligonucleotide (L7), containing the SA-responsive element previously identified in the $P R-1$ promoter (Lebel et al. 1998), was used as a probe in a gel-retardation assay. Its sequence is $5^{\prime}$ TTACTTACGTCATAGATGTGGC 3', while that of the mutant form (M-L7) is $5^{\prime}$ TTACTTTTTCTAGA TGTGTGGC 3'. The complementary strands were annealed and subsequently labeled with polynucleotide kinase and $\gamma$ ${ }^{32} \mathrm{P}$-ATP. Gel-retardation assays were carried essentially as described previously (Perisic and Lam 1992). Briefly, the histidine-tagged TGA 2 or TGA3 were incubated in EB buffer (20 mM HEPES [ $N$-2-hydroxyethylpiperazine- $N$-2-ethanesulfonic acid] $\mathrm{pH} 7.0,40 \mathrm{mM} \mathrm{KCl}, 0.5 \mathrm{mM}$ EDTA, $10 \%$ glycerol, 1 $\mathrm{mM}$ DTT [dithiothreitol]) in the presence of $0.4 \mu \mathrm{g}$ of poly $(\mathrm{dI}-\mathrm{dC}), 0.5 \mathrm{ng}$ of ${ }^{32} \mathrm{P}$-labeled DNA probe with or without unlabeled probe as a competitor for $30 \mathrm{~min}$ at room temperature. The DNA-protein complex was separated by electrophoresis on a $4 \%$ native polyacrylamide gel in 0.25 TBE (Tris-borateEDTA) buffer. The gel was dried before autoradiography.

\section{ACKNOWLEDGMENTS}

We thank William Crosby for kindly providing the Arabidopsis prey library. We gratefully acknowledge D'Maris Dempsey for critical reading of the manuscript. This work was made possible by grants from the National Science Foundation (no. MCB-9723952) to D. F. K. and from the National Institutes of Health (no. R21GM45574-07) to E. L.

\section{LITERATURE CITED}

Baeuerle, P., and Baltimore, D. 1996. NF-кB: Ten years after. Cell 87: 13-20.

Bowling, S. A., Clarke, J. D., Liu, Y., Klessig, D. F., and Dong, X. 1997. The cpr 5 mutant of Arabidopsis expresses both NPR1-dependent and NPR1-independent resistance. Plant Cell 9:1573-1584.

Bowling, S. A., Guo, A., Cao, H., Gordon, A. S., Klessig, D. F., and Dong, X. 1994. A mutation in Arabidopsis that leads to constitutive expression of systemic acquired resistance. Plant Cell 6:1845-1857.
Cao, H., Bowling, S.A., Gordon, A.S., and Dong, X. 1994. Characterization of an Arabidopsis mutant that is nonresponsive to inducers of systemic acquired resistance. Plant Cell 6:1583-1592.

Cao, H., Glazebrook, J., Clarke, J. D., Volko, S., and Dong, X. 1997. The Arabidopsis NPRl gene that controls systemic acquired resistance encodes a novel protein containing ankyrin repeats. Cell 88:57-63.

Cao, H., Li, X., and Dong, X. 1998. Generation of broad-spectrum disease resistance by overexpression of an essential regulatory gene in systemic acquired resistance. Proc. Natl. Acad. Sci. USA 95:65316536.

Chen, W., Chao, G., and Singh, K. B. 1996. The promoter of a $\mathrm{H}_{2} \mathrm{O}_{2}$ inducible, Arabidopsis glutathione $S$-transferase gene contains closely linked OBF- and OBP1-binding sites. Plant J. 10:955-966.

Clarke, J. D., Liu, Y., Klessig, D. F., and Dong, X. 1998. Uncoupling PR gene expression from NPR1 and bacterial resistance: Characterization of the dominant Arabidopsis cpr6-1 mutant. Plant Cell 10:557-569.

Delaney, T. P., Friedrich, L., and Ryals, J. A. 1995. Arabidopsis signal transduction mutant defective in chemically and biologically induced disease resistance. Proc. Natl. Acad. Sci. USA 92:6602-6606.

Delaney, T. P., Uknes, S., Vernooij, B., Friedrich, L., Weymann, K., Negrotto, D., Gaffney, T., Gut-Rella, M., Kessmann, H., Ward, E., and Ryals, J. 1994. A central role of salicylic acid in plant disease resistance. Science 266:1247-1250.

Dempsey, D., Shah, J., and Klessig, D. F. 1999. Salicylic acid and disease resistance in plants. Crit. Rev. Plant Sci. 18:547-575.

Dietrich, R. A., Delaney, T. P., Uknes, S. J., Ward, E. R., Ryals, J. A., and Dangl, J. L. 1994. Arabidopsis mutants simulating disease resistance response. Cell 77:565-577.

Fields, S., and Song, O. K. 1989. A novel genetic system to detect protein-protein interactions. Nature 340:245-246.

Gaffney, T., Friedrich, L., Vernooij, B., Negrotto, D., Nye, G., Uknes, S., Ward, E., Kessmann, H., and Ryals, J. 1993. Requirement of salicylic acid for the induction of systemic acquired resistance. Science 261: 754-756.

Gietz, R., Schiestl, R., Willems, A., and Woods, R. 1995. Studies on the transformation of intact yeast cells by the LiAc/SS-DNA/PEG procedure. Yeast 15:355-360.

Glazebrook, J., Rogers, E. E., and Ausubel, F. M. 1996. Isolation of Arabidopsis mutants with enhanced disease susceptibility by direct screening. Genetics 143:973-982.

Gorina, S., and Pevletich, N. P. 1996. Structure of the p53 tumor suppressor bound to the ankyrin and $\mathrm{SH} 3$ domains of 53BP2. Science 274:1001-1005.

Greenberg, J. T., Guo, A., Klessig, D. F., and Ausubel, F. M. 1994. Programmed cell death in plants: A pathogen-triggered response activated coordinately with multiple defense functions. Cell 77:551-563.

Ho, S., Hunt, H., Horton, R., Pullen, J., and Pease, L. 1989. Site-directed mutagenesis by overlap extension using the polymerase chain reaction. Gene 15:51-59.

Hoffman, C. 1994. Preparation of yeast DNA, RNA and proteins. Pages 13.11.1-13.11.4 in: Current Protocols in Molecular Biology. F. Ausubel, R. Brent, R. Kinston, D. Moore, J. Seidman, J. Smith, and K. Struhl, eds. John Wiley and Sons, New York.

James, P., Halladay, J., and Craig, E. A. 1996. Genomic libraries and a host strain designed for highly efficient two-hybrid selection in yeast. Genetics 144:1425-1436.

Jupin, I., and Chua, N.-H. 1996. Activation of the CaMV as-1 ciselement by salicylic acid: Differential DNA binding of a factor related to TGA1a. EMBO J. 15:5679-5689.

Katagiri, F., Lam, E., and Chua, N.-H. 1989. Two tobacco DNA-binding proteins with homology to the nuclear factor CREB. Nature 340:727730 .

Krappmann, D., Wulczyn, F. G., and Scheidereit, C. 1996. Different mechanisms control signal-induced degradation and basal turnover of

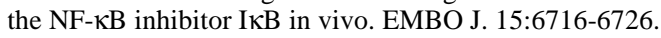

Lebel, E., Heifetz, P., Thorne, L., Uknes, S., Ryals, J., and Ward, E. 1998. Functional analysis of regulatory sequences controlling PR-1 gene expression in Arabidopsis. Plant J. 16:223-233.

Malamy, J., and Klessig, D. F. 1992. Salicylic acid and plant disease resistance. Plant J. 2:643-654.

Mauch-Mani, B., and Slusarenko, A. J. 1996. Production of salicylic acid precursors is a major function of phenylalanine ammonia-lyase in the resistance of Arabidopsis to Peronospora parasitica. Plant Cell 8: 203-212. 
Meisel, L., and Lam, E. 1997. Switching on gene expression: Analysis of the factors that spatially and temporally regulate plant gene expression. Genet. Eng. 19:183-199.

Pallas, J. A., Paiva, N. L., Lamb, C., and Dixon, R. A. 1996. Tobacco plants epigenetically suppressed in phenylalanine ammonia-lyase expression do not develop systemic acquired resistance in response to infection by tobacco mosaic virus. Plant J. 10:281-293.

Perisic, O., and Lam, E. 1992. A tobacco DNA binding protein that interacts with a light-responsive box II element. Plant Cell 4:831-838.

Pieterse, C. M. J., van Wees, S. C. M., van Pelt, J. A., Knoester, M., Laan, R., Gerrits, H., Weisbeek, P. J., and van Loon, L. C. 1998. A novel signaling pathway controlling induced systemic resistance in Arabidopsis. Plant Cell 10:1571-1580.

Ryals, J., Weymann, K., Lawton, K., Friedrich, L., Ellis, D., Steiner, H.Y., Johnson, J., Delaney, T. P., Jesse, T., Vos, P., and Uknes, S. 1997. The Arabidopsis NIM1 protein shows homology to the mammalian transcription factor inhibitor IאB. Plant Cell 9:425-439.

Ryals, J. A., Neuenschwander, U. H., Willits, M. G., Molina, A., Steiner, H.-Y., and Hunt, M. D. 1996. Systemic acquired resistance. Plant Cell 8:1809-1819.

Shah, J., Kachroo, P., and Klessig, D. F. 1999. The Arabidopsis ssil mutation restores pathogenesis-related gene expression in $n p r l$ plants and renders defensin gene expression salicylic acid dependent. Plant Cell 11:191-206.

Shah, J., Tsui, F., and Klessig, D. F. 1997. Characterization of a salicylic acid-insensitive mutant (sail) of Arabidopsis thaliana, identified in a selective screen utilizing the SA-inducible expression of the tms 2 gene. Mol. Plant-Microbe Interact. 10:69-78.

Silva, H., Yoshioka, K., Dooner, H. K., and Klessig, D. F. 1999. Characterization of a new Arabidopsis mutant exhibiting enhanced disease resistance. Mol. Plant-Microbe Interact. 12:1053-1063.

Stange, C., Ramírez, I., Gómez, I., Jordana, X., and Holuigue, L. 1997. Phosphorylation of nuclear proteins directs binding to salicylic acid- responsive elements. Plant J. 11:1315-1324.

Strompen, G., Grüner, R., and Pfitzner, U. M. 1998. An as-1-like motif controls the level of expression of the gene for the pathogenesisrelated protein 1a from tobacco. Plant Mol. Biol. 37:871-883.

Ulmasov, T., Ohmuya, A., Hagen, G., and Guilfoyle, T. 1995. The soybean $\mathrm{GH} 2 / 4$ gene that encodes a glutathione $S$-transferase has a promoter that is activated by a wide range of chemical agents. Plant Physiol. 108:919-927.

Wang, H., Fowke, L., and Crosby, W. 1997. A plant cyclin-dependent kinase inhibitor gene. Nature 386:451-452.

Weymann, K., Hunt, M., Uknes, S., Neuenschwander, U., Lawton, K., Steiner, H.-Y., and Ryals, J. 1995. Suppression and restoration of lesion formation in Arabidopsis $l s d$ mutants. Plant Cell 7:2013-2022.

Whiteside, S. T., and Israël, A. 1997. IкB proteins: Structure, function and regulation. Semin. Cancer Biol. 8:75-82.

Xiang, C., Miao, Z. H., and Lam, E. 1996. Coordinated activation of as 1 type elements and a tobacco gluthione $S$-transferase gene by auxins, salicylic acid, methyl-jasmonate and hydrogen peroxide. Plant Mol. Biol. 32:415-426.

Xiang, C., Miao, Z. H., and Lam, E. 1997. DNA-binding properties, genomic organization and expression pattern of TGA6, a new member of the TGA family of bZIP transcription factors in Arabidopsis thaliana. Plant Mol. Biol. 34:403-415.

Yu, I.-C., Parker, J., and Bent, A. F. 1998. Gene-for-gene disease resistance without the hypersensitive response in Arabidopsis dndl mutant. Proc. Natl. Acad. Sci. USA 95:7819-7824.

Zhang, B., Foley, R. C., and Singh, K. B. 1993. Isolation and characterization of two related Arabidopsis ocs-element bZIP binding proteins. Plant J. 4:711-716.

Zhang, Y., Fan, W., Kinkema, M., Li, X., and Dong, X. 1999. Interaction of NPR1 with basic leucine zipper protein transcription factors that bind sequences required for salicylic acid induction of $P R-1$ gene. Proc. Natl. Acad. Sci. USA 96:6523-6528. 